\title{
Clinicopathological analysis of PD-L2 expression in colorectal cancer
}

This article was published in the following Dove Press journal:

OncoTargets and Therapy

\author{
Peng-Da Guo',* \\ Zhong-Wen Sun ${ }^{1, *}$ \\ Hui-Jun Lai \\ Jie Yang' \\ Ping-Ping $\mathrm{Wu}^{\prime}$ \\ Yun-Di Guo' \\ Jing Sun'
}

'Institute of Medical Technology, Suzhou Vocational Health College, Suzhou, Jiangsu 215009, China;

${ }^{2}$ Department of Ultrasound, Suzhou Traditional Chinese Medicine, Suzhou, Jiangsu 215007, China

*These authors contributed equally to this work
Correspondence: Jing Sun

Institute of Medical Technology, Suzhou Vocational Health College, No 28 of

Kehua Road, Suzhou, Jiangsu 215009 ,

China

Tel +8605 I26 2690083

Fax +86 05 I26 2690192

Email jsun@szhct.edu.cn
Background: (PD-L2), a ligand of programmed cell death protein 1 (PD-1), is an inhibitory receptor of T cells and activated $B$ cells. Many studies have focused on PD-L1, another ligand of PD-1, and the prognostic significance of PD-L1 has been reported in many tumors. However, the expression of PD-L2 in relation to clinical outcomes has not been fully investigated in cancer patients.

Patients and methods: In this study, we investigated the expression of PD-L2 via immunohistochemistry (IHC) in the pathological specimens of 348 patients treated for colorectal cancer (CRC).

Results: Strong PD-L2 expression was found in the cancer tissues from $41 \%$ of the CRC patients who also had a high TNM stage and carcinoembryonic antigen (CEA) concentration. We also carried out functional studies in vitro, which showed that PD-L2 did not influence the growth of the CRC cell line HCT116, but increased cell invasion.

Conclusion: Collectively, these findings suggest that PD-L2 may be a potential therapeutic target for CRC.

Keywords: PD-L2, colorectal cancer, migration, therapeutic target

\section{Introduction}

Colorectal cancer (CRC) is the second most prevalent cancer in women and the third most common cancer in men, according to WHO. ${ }^{1}$ Despite recent advances in CRC prognosis, diagnosis, and treatment, there are 1.38 million reported cases of CRC and approximately 700,000 deaths from CRC in 2012 worldwide. ${ }^{2}$

The immune system plays a pivotal role in both the surveillance and destruction of tumors, and this mechanism has been exploited to produce new treatment options that have garnered much success in some types of tumors. Costimulatory molecules that regulate the immune system have been reported to upregulate or downregulate immune responses. Costimulatory molecules include the $\mathrm{B} 7$ protein family members and TNF- $\alpha$ family members, such as CTLA-4, CD28, and CD40.

The B7 family member programmed-death-1-ligand 2 (PD-L2/B7-DC) was identified in dendritic cells (DCs) in 2001. This molecule is one ligand of programmed cell death protein 1 (PD-1), ${ }^{3}$ an inhibitory receptor of T cells and activated B cells. PD-1 and PD-Ls are key checkpoint molecules in the immune system and mediate interactions between $\mathrm{T}$ cells and antigen-presenting cells (APCs) or host cells, helping cancer cells evade host immune surveillance. ${ }^{4}$ It is commonly accepted that PD-L1 expressed on tumor cells can inhibit the T-cell antitumor response and facilitate cancer development. However, a study done in CRC tissues has shown that the expression of PD-L1 is only positive in a limited percentage (approximately 10\%) of tumors, ${ }^{5}$ which does not explain how CRC cells evade the antitumor immune response in the absence of PD-L1 expression. 
PD-L2, the other ligand of PD-1, was found to be moderately or strongly expressed in most tumor cells, suggesting functional relevance to the tumor microenvironment. Several studies have shown that PD-L2 plays an inhibitory role through interacting with the PD-1 receptor. ${ }^{6,7}$ However, a study suggests that PD-L2 can stimulate T-cell proliferation via a PD-1 receptor-independent mechanism that potentially involves a distinct PD-L2 binding partner. ${ }^{8}$

In this study, we carried out immunohistochemistry (IHC) to investigate the expression pattern of PD-L2 in CRC. Results showed that PD-L2 was highly expressed, and its expression was correlated with TNM stage and the tumor-associated antigen, carcinoembryonic antigen (CEA). Moreover, we used in vitro assays to investigate the role of PD-L2 in tumor proliferation and invasion. Taken together, these results establish an important role for PD-L2 in cancer progression and suggest an underlying suppression of cancer immune surveillance.

\section{Patients and methods}

\section{Patients}

Specimens from 348 patients who had been diagnosed with CRC were examined. Patients who had received preoperative chemotherapy or radiotherapy were excluded. Of these patients, 225 cases were from the Department of General Surgery of Shanghai Renji Hospital, and the other 123 cases were from the Department of General Surgery of Kunshan People Hospital and the Suzhou Municipal Hospital, Jiangsu, China, between January 2009 and December 2010. All 348 of the cases were diagnosed as CRC via H\&E staining after surgical resection. Pathological reports of these patients were recorded, and their clinical parameters are shown in Table 1. Survival data were collected through patient follow-up. Prior to commencing the experiments in this study, the approval from the ethics review board of Suzhou Vocational Health Technology College was granted, and written informed consent was obtained from each tissue donor.

\section{Cell culture and antibodies}

The CRC cell line HCT116 was purchased from the Shanghai Cell Biology Institutes, Chinese Academy of Science (Shanghai, China). Cells were cultured at $37^{\circ} \mathrm{C}$ in a humidified incubator supplemented with $5 \% \mathrm{CO}_{2}$. Rabbit anti-human PD-L2 (1:100) monoclonal antibody (ab200377) was purchased from Abcam (Cambridge, MA, USA). The secondary antibody was purchased from Maixin_bio ${ }^{\mathrm{TM}}$ (Fujian, China).

\section{Construction of tissue microarray (TMA)}

TMAs were constructed. Area-specialized histopathologists identified and marked formalin-fixed paraffin-embedded tissue blocks containing tumor tissues on H\&E-stained slides. Replicate (two) $1.6 \mathrm{~mm}$ cores from the center and periphery of the tumors were taken and arrayed into a recipient paraffin block using a tissue puncher/arrayer (patent number: 200920350099. 2 P. R. China). Nine-micrometer sections of the tissue array block were cut, deparaffinized, and dehydrated for immunohistochemical staining.

\section{IHC}

Immunohistochemical staining for PD-L2 was performed according to the manufacturer's instructions. In brief, antigens were retrieved by EDTA solution. Sections were cooled down and immersed in $0.3 \% \mathrm{H}_{2} \mathrm{O}_{2}$ solution for 20 minutes to block the endogenous peroxidase activity, and then rinsed in PBS for 5 minutes, blocked with 5\% BSA at room temperature for 20 minutes, and incubated with primary antibodies against PD-L2 (1:100 dilution, $19 \mu \mathrm{g} / \mathrm{mL}$ final concentration) at $4^{\circ} \mathrm{C}$ overnight. A universal biotinylated secondary antibody was developed. Sections were dehydrated, cleared, and mounted.

\section{Evaluation of immunohistochemical staining}

Sufficient tissues were observed for immunohistochemical evaluation of PD-L2 expression by two independent pathologists who were blinded to the clinicopathological parameters of the CRC patients. A semiquantitative scoring scheme based on the distribution of positive tumor cells and the staining intensity was used to evaluate the expression of PD-L2. The distribution score, which is an estimate of the percentage of positively stained cells, was multiplied by an intensity factor, which ranged from 1 (staining intensity just exceeding background) to 4 (dark brown staining obvious on macroscopic inspection of the slide). At the same time, the intensity ratio of positively stained cells was also evaluated as follows: $0 \%-10 \%$ staining scored $0,11 \%-30 \%$ staining scored 1, 31\%-60\% staining scored 2, and 61\%-100\% staining scored 3 . The gene expression score was calculated by multiplying the two scores and dividing by 4 . A score of $0-1$ was designated as low expression, and a score of 2-3 as high expression. PD-L2 expression in tumor cells was evaluated.

\section{Cell proliferation assay}

PD-L2 protein used in the in vitro experiment was purchased from R\&D Systems, Inc. (Minneapolis, MN, USA; Accession \#: Q9BQ51). Proliferation was determined using a 
Table I The association between PD-L2 expression and clinical pathological characteristics

\begin{tabular}{|c|c|c|c|c|c|}
\hline Characteristics & $\begin{array}{l}\text { Total } \\
\mathbf{N}=348\end{array}$ & $\begin{array}{l}\text { PD-L2 } \\
\text { expression } \\
\text { (low) } \mathbf{N}=205\end{array}$ & $\begin{array}{l}\text { PD-L2 } \\
\text { expression } \\
\text { (high) } \mathbf{N}=143\end{array}$ & Chi-square & $P$-value \\
\hline Age (years), n (\%) & 348 & $205(58.9)$ & $143(4 \mid . I)$ & 1.982 & 0.159 \\
\hline$<60$ & $142(40.8)$ & $90(25.9)$ & $52(14.9)$ & & \\
\hline$\geq 60$ & $206(59.2)$ & $115(33.1)$ & $91(26.1)$ & & \\
\hline Gender, n (\%) & 348 & $205(58.9)$ & I53 (4I.I) & 0.782 & 0.376 \\
\hline Male & $227(63.4)$ & $126(36.2)$ & I0I (29.0) & & \\
\hline Female & $131(36.6)$ & $79(22.7)$ & $42(12.1)$ & & \\
\hline Tumor site, n (\%) & 348 & $205(58.9)$ & I43 (4I.I) & 1.927 & 0.165 \\
\hline Colon & $161(46.3)$ & $101(29.0)$ & $60(17.2)$ & & \\
\hline Rectum & $186(53.4)$ & $104(29.9)$ & $83(23.9)$ & & \\
\hline Pathology grading, n (\%) & 348 & $205(58.9)$ & $143(4 \mid . I)$ & 2.567 & 0.277 \\
\hline Well-differentiated & $142(40.8)$ & $78(22.4)$ & $64(18.4)$ & & \\
\hline Moderate differentiated & $139(39.9)$ & $89(25.6)$ & $50(14.4)$ & & \\
\hline Poor-differentiated & $67(19.3)$ & $38(10.9)$ & $29(8.3)$ & & \\
\hline Stage (TNM), n (\%) & 348 & $205(58.9)$ & $143(4 \mid . I)$ & 9.05 & 0.029 \\
\hline 1 & $74(21.3)$ & $48(13.8)$ & $26(7.5)$ & & \\
\hline II & $114(32.8)$ & $71(20.4)$ & $43(12.4)$ & & \\
\hline III & $110(31.6)$ & $66(19.0)$ & $44(12.6)$ & & \\
\hline IV & $50(14.4)$ & $20(5.7)$ & $30(8.6)$ & & \\
\hline Tumor volume $\left(\mathrm{mm}^{3}\right), \mathrm{n}(\%)$ & 348 & $205(58.9)$ & I43 (4I.I) & 0.363 & 0.546 \\
\hline$<35$ & $211(60.6)$ & $127(36.5)$ & $84(24.1)$ & & \\
\hline$\geq 35$ & $137(39.4)$ & $78(22.4)$ & $59(17.0)$ & & \\
\hline Lymph node metastasis, n (\%) & 348 & $205(58.9)$ & $143(4 \mid . I)$ & 4.304 & 0.038 \\
\hline Negative & $160(46.0)$ & $109(31.3)$ & $5 I(14.7)$ & & \\
\hline Positive & $188(54.0)$ & $96(27.6)$ & $92(26.4)$ & & \\
\hline Distant metastasis, n (\%) & 338 & $205(60.7)$ & $133(39.3)$ & 0.3192 & 0.572 \\
\hline Negative & $311(92.0)$ & $190(56.2)$ & $121(35.8)$ & & \\
\hline Positive & $27(8.0)$ & $15(4.4)$ & $12(3.6)$ & & \\
\hline Tumor gross type, n (\%) & 268 & $132(49.3)$ & $136(50.7)$ & 0.944 & 0.624 \\
\hline Mass forming & $81(30.2)$ & $49(18.3)$ & $32(11.9)$ & & \\
\hline Infiltrative & $97(36.3)$ & $62(23.1)$ & $35(13.1)$ & & \\
\hline Ulcerative & $90(33.6)$ & $21(7.8)$ & $69(25.7)$ & & \\
\hline Preoperative CEA (ng/mL), n (\%) & 348 & $205(58.9)$ & I43 (4I.I) & 11.3 & 0.004 \\
\hline$<5$ & $183(52.6)$ & $121(34.8)$ & $62(17.8)$ & & \\
\hline$\geq 5$ & $165(47.4)$ & $84(24.1)$ & $81(23.3)$ & & \\
\hline
\end{tabular}

Abbreviations: CEA, carcinoembryonic antigen; PD-L2, programmed-death-I-ligand 2.

Cell Counting Kit-8 (CCK-8; Dojindo, Kumamoto, Japan) for the last 5 hours of a 24-hour incubation period. In the CCK-8 assay, HCT116 cells were normalized at 5,000 cells $/ 100 \mu \mathrm{L}$ in 96-well plates. In the PD-L2-Fc protein groups, HCT116 cells were incubated with $0.5-20 \mathrm{mg} / \mathrm{mL}$ PD-L2-Fc. After 24 hours of incubation, the cells were analyzed via the CCK-8 assay at $650 \mathrm{~nm}$, as described by the manufacturer's protocol. Three replicate wells were used to determine each data point, and four different experiments were performed.

\section{Cell invasion assay}

The in vitro invasion assay was performed using $8 \mu \mathrm{m}$ pore size Transwell ${ }^{\circledR}$ inserts ( $\# 3422$, Corning Incorporated, Corning, NY, USA). HCT116 cells $(10,000)$ were placed on the top of the Transwell ${ }^{\circledR}$ chamber inserts, and serum (10\%) was used as the chemoattractant. Before cell seeding, the transwell chambers were plated with $50 \mu \mathrm{L}$ Matrigel (diluted 1:5 in serum-free media) and incubated for 4 hours at $37^{\circ} \mathrm{C}$. Lower compartments contained RPMI 1640 medium with 
$10 \%$ FBS. After 24 hours of incubation at $37^{\circ} \mathrm{C}$ in a humidified chamber with $5 \% \mathrm{CO}_{2}$, non-invading cells and gel were removed from the upper chamber using cotton-tipped swabs. Cells were fixed with methanol for 30 minutes and stained with crystal violet. Invading cells were counted in three random fields per filter at $200 \times$ magnification for triplicate wells. This experiment was conducted in triplicate.
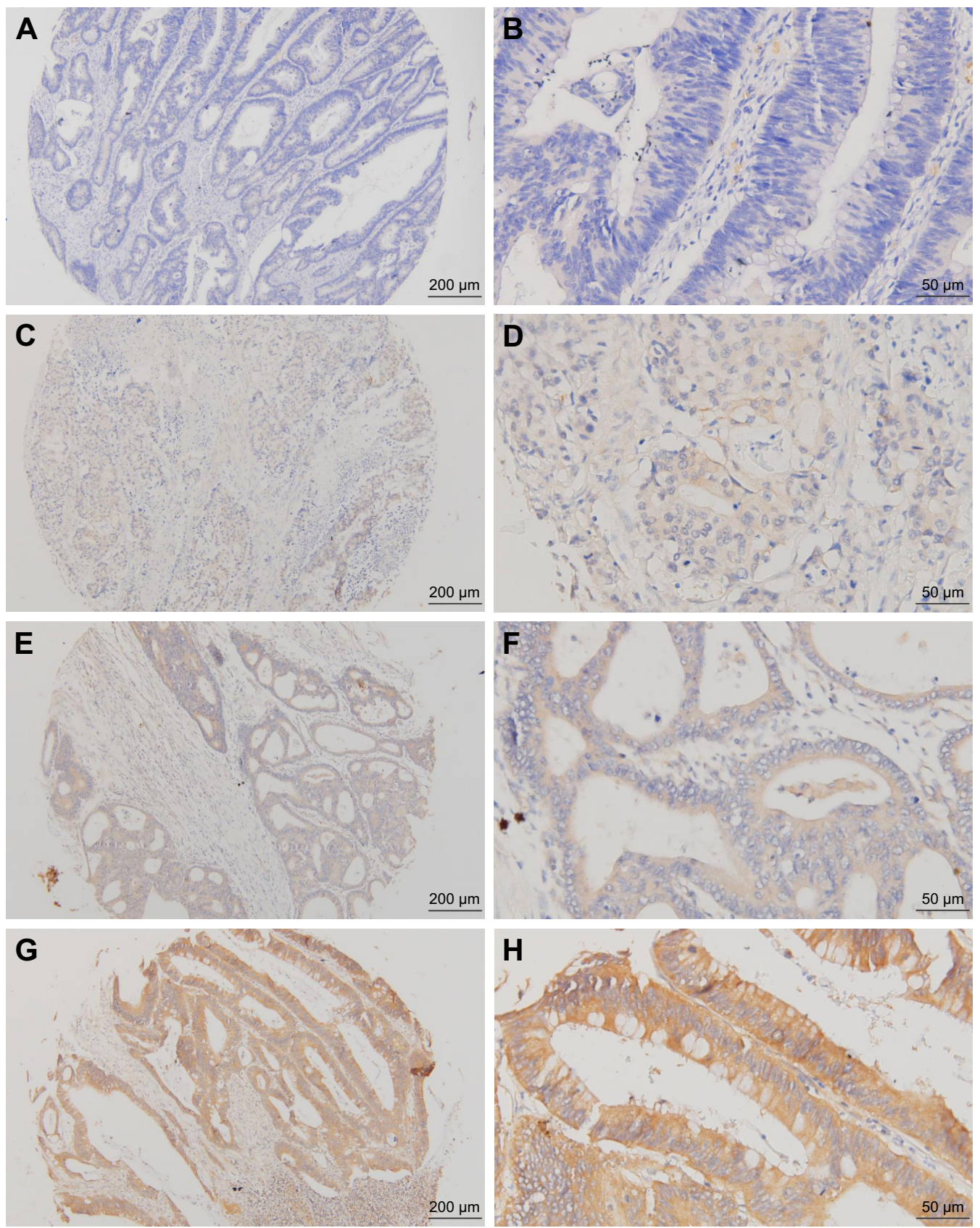

Figure I Representative immunohistochemical staining of PD-L2 expression in human CRC.

Note: (A) Negative $\times 100$, (B) negative $\times 400$, (C) weak positive $\times 100$, (D) weak positive $\times 100$, (E) moderate positive $\times 100$, (F) moderate positive $\times 400$, (G) strong positive $\times 100$, and $(\mathbf{H})$ strong positive $\times 400$. Scale bar represents $50 \mu \mathrm{m}$.

Abbreviations: CRC, colorectal cancer; PD-L2, programmed-death-I-ligand 2.
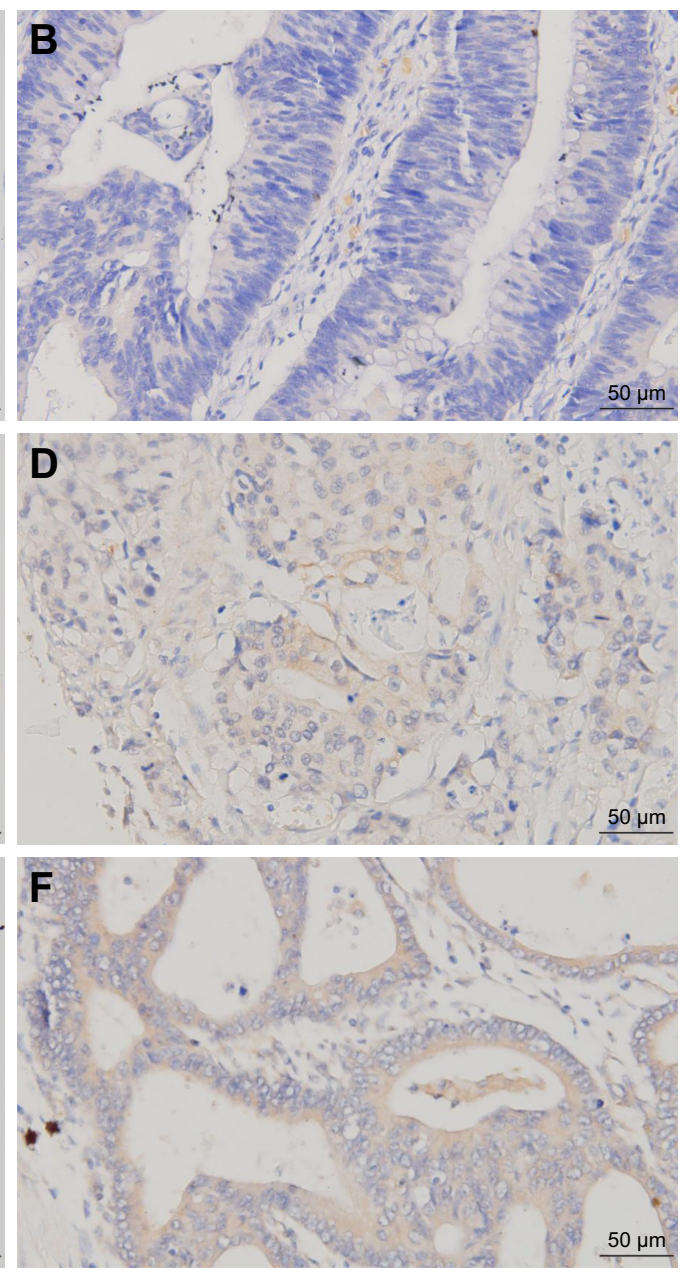

\section{Results Expression of PD-L2 in CRC tissues}

To assess the diversity of PD-L2 expression in CRC, immunohistochemical analysis was performed, and the results revealed that PD-L2 expression was present in tissues from 273 of the $348 \mathrm{CRC}$ cases (78.45\%). Different levels of PD-L2 expression are shown in Figure 1. Through the 
IHC results, we observed that PD-L2 was predominantly expressed in the membrane and cytoplasm of tumor cells.

\section{Correlation of PD-L2 expression with patient clinical parameters}

We analyzed PD-L2 expression in CRC tissues and found that the expression had a negative correlation with lymph node metastasis and tumor stage $(P=0.038$ and 0.029$)$, suggesting that PD-L2 is involved in cancer invasion. PD-L2 expression levels, however, were not correlated with other clinicopathological parameters, such as gender, age, tumor location, tumor size, pathology grading, tumor gross type, and distant metastasis (Table 1).

\section{Correlation of PD-L2 expression with tumor markers}

Detection of biomarkers in circulation is a convenient and economical screening method. There are three tumor biomarkers for CRC that are widely used in clinical settings: CEA, carbohydrate antigen 199 (CA199), and carbohydrate antigen 125 (CA125). In this study, we found that CRC patients with highly expressed PD-L2 had a higher serum CEA concentration (Figure 2).

\section{PD-L2 had no effect on the proliferation of HCTI 16 cells}

To evaluate the role of PD-L2 in CRC, we carried out proliferation assays in vitro using the HCT116 cell line incubated with a PD-L2-Fc fusion protein for 24 hours. Results showed that there was no difference in cellular proliferation between the PD-L2 fusion protein group and the control group (Figure 3). The experiments were duplicated three times.

\section{PD-L2 increased HCTII6 cell invasion}

To further determine the relationship of PD-L2 with cell invasion in CRC, we performed Transwell ${ }^{\circledR}$ invasion assays to examine the effects of PD-L2 on the invasion of HCT116 cells. We found that the PD-L2-Fc protein significantly increased the transmembrane cell numbers compared with that of the negative control group $(P<0.005$; Figure 4$)$ and this effect was dose-dependent (Figure 3). After 24 hours of culture in Transwell ${ }^{\circledR}$ chambers, the average number of
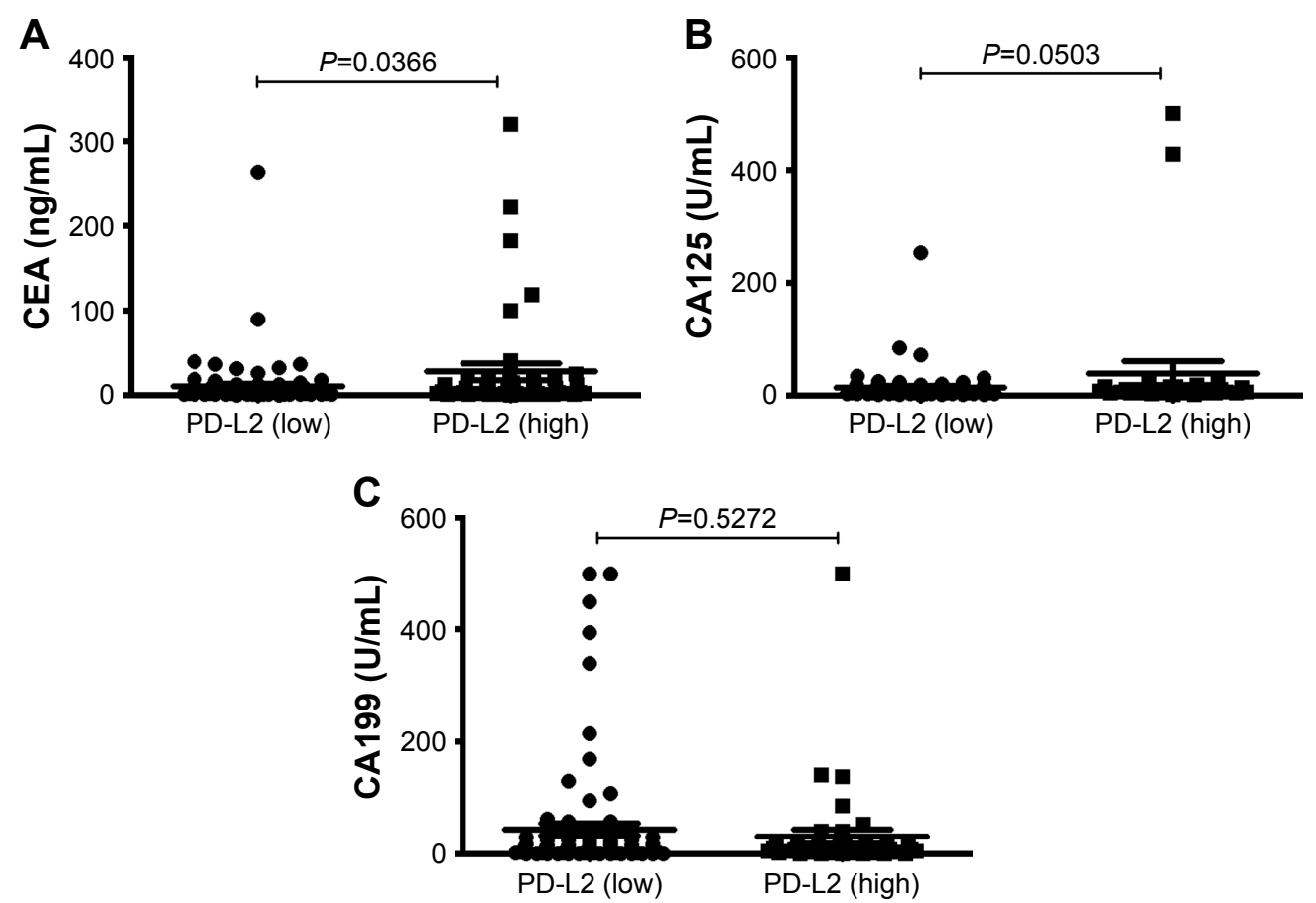

Figure 2 Levels of serum tumor markers in CRC tissues with different PD-L2 expression levels.

Notes: (A) A statistical difference CEA levels among the different PD-L2 expression levels. (B) CA-I25 levels among the different PD-L2 expression levels. (C) CA-I99 levels among the different PD-L2 expression levels.

Abbreviations: CA-125, carbohydrate antigen 125; CA-199, carbohydrate antigen 199; CEA, carcinoembryonic antigen; PD-L2, programmed-death-I-ligand 2. 


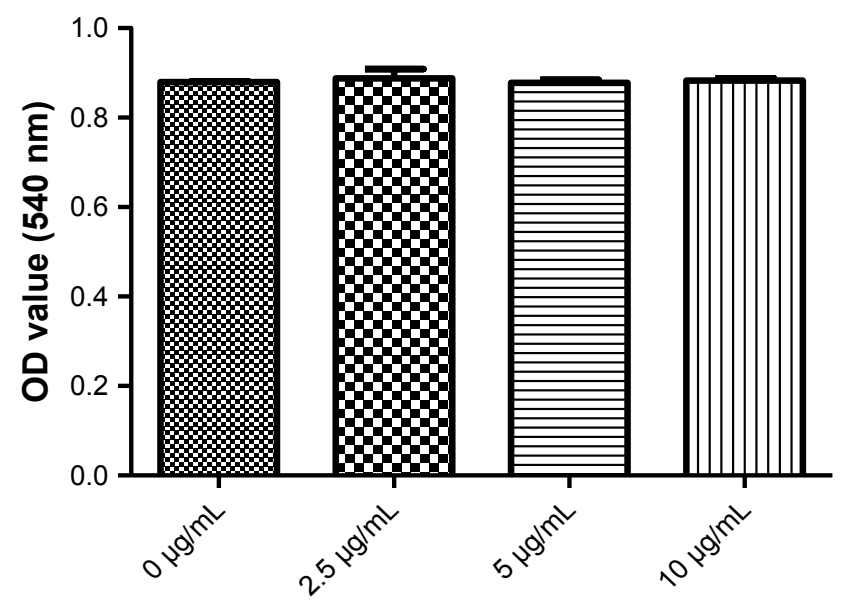

Figure 3 There was no effect of PD-L2 on cell growth in the CRC cell line. Note: CCK- 8 assays were conducted 24 hours after HCTI 19 cells were plated. Abbreviations: CCK-8, Cell Counting Kit-8; CRC, colorectal cancer; PD-L2, programmed-death-I-ligand 2.

cells passing through the membrane was $243 \pm 23.3$. However, when the PD-L2-Fc fusion protein $(10 \mu \mathrm{g} / \mathrm{mL})$ was added into the lower chamber, the cell number increased to $598 \pm 39.4$. These results suggest that PD-L2 is involved in malignant progression and metastasis.

\section{Discussion}

PD-L2, a second ligand of PD-1, generally has a lower expression level than PD-L1. ${ }^{9}$ PD-L2 was initially restricted to APCs, including macrophages, DCs, mast cells, and some B cells. ${ }^{10,11}$ More recently, however, several groups have shown that PD-L2 expression can be induced in various other immune and non-immune cells. ${ }^{12}$ PD-L2 was detected in activated $\mathrm{T}$ cells ${ }^{13}$ and various solid tumors, such as renal cell carcinoma, bladder carcinoma, melanoma, non-small-cell lung cancer (NSCLC), head and neck squamous carcinoma, breast cancer, ovarian carcinoma, and hepatocellular carcinoma (HCC). ${ }^{14-16}$ Of the two ligands of PD-1, the majority of studies focused on PD-L1 expression in various tumor tissues and found a significant correlation between PD-L1 expression and patient prognosis after surgery. Less research has been done regarding the clinical significance of PD-L2. Therefore, we performed IHC to observe PD-L2 expression in CRC tissues and found a high level of expression (85\%), which is consistent with the PD-L2 expression level of $85.5 \%$ in CRC tissue cells reported by Wang et $\mathrm{al}^{17}$ and $84.8 \%$ in gastric cancer reported by Dong et al. ${ }^{18}$ However, some studies found PD-L2 expression to be either negative or weakly positive in a majority of tumor cells, such as in ovarian cancer as reported by Hamanishi et al. ${ }^{19}$ In addition, Nomi et a ${ }^{20}$ reported that only $27 \%$ of the analyzed pancreatic tumors expressed PD-L2.
PD-L2 is a costimulatory molecule that plays an inhibitory role in regulating $\mathrm{T}$ cell activation during the immune response. PD-L2 was shown to interact with PD-1 and dramatically inhibits $\mathrm{T}$ cell receptor (TCR)-mediated proliferation and cytokine production by $\mathrm{CD} 4^{+} \mathrm{T}$ cells..$^{21}$ Cancer evades host immune surveillance via the utilization of immune checkpoints. ${ }^{22,23}$ These checkpoints include PD-1/ PD-L1 (or PD-L2)-mediated interactions between T cells and tumor cells to inhibit their function. The relationship between PD-L2 and tumor prognosis remains controversial. Rozali et al reported that PD-L2-positive esophageal carcinoma patients had a poorer prognosis than PD-L2-negative patients. ${ }^{9}$ Jung et al reported that PD-L2 expression was a significant prognostic factor for the overall survival of patients with $\mathrm{HCC} .{ }^{24}$ In our investigation, the overexpression of PD-L2 was found to be significantly correlated with histological differentiation, TNM stage, and preoperative CEA. Our results support the hypothesis that PD-L2 expression aids tumor cells in escaping immune surveillance. The results were consistent with a paper published in 2017 by Wang et al, ${ }^{17}$ which reported that PD-L2 was overexpressed in CRC tissue cells and correlated with poor patient survival. Although the suppression of T-cell responses by PD-L2 has been shown in numerous studies, the specific effects of PD-L2 still seem to vary, potentially due to differences in tissue type and heterogeneity of the immune background. To illuminate the mechanism behind the role of PD-L2 in immune escape, we carried out experiments in vitro. We observed no obvious effect of the PD-L2 fusion protein on proliferation in HCT116 CRC cells in the CCK-8 assays. However, the invasion of HCT116 cells following treatment with PD-L2 was significantly increased, suggesting a correlation between PD-L2 expression and TNM stage in clinical data. It has been reported that there is an alternative, secondary receptor for PD-L2 called RGMb. ${ }^{25}$ RGMb is a member of the repulsive guidance molecule (RGM) family, and its expression increases with CRC progression in human patients. RGMb inhibited apoptosis and increased the viability of CRC cells lines. ${ }^{26}$ We speculate that PD-L2 in tumor cells may function through interactions with other receptors such as RGMb. The exact mechanism needs to be further researched.

\section{Conclusion}

This study demonstrated that PD-L2 was expressed in approximately $85 \%$ of the CRC tissues, and this expression was associated with histological differentiation, TNM stage, and preoperative CEA. The in vitro experiments also provided evidence that PD-L2 is involved in tumor cell invasion. Thus, these findings provide comprehensive information and 

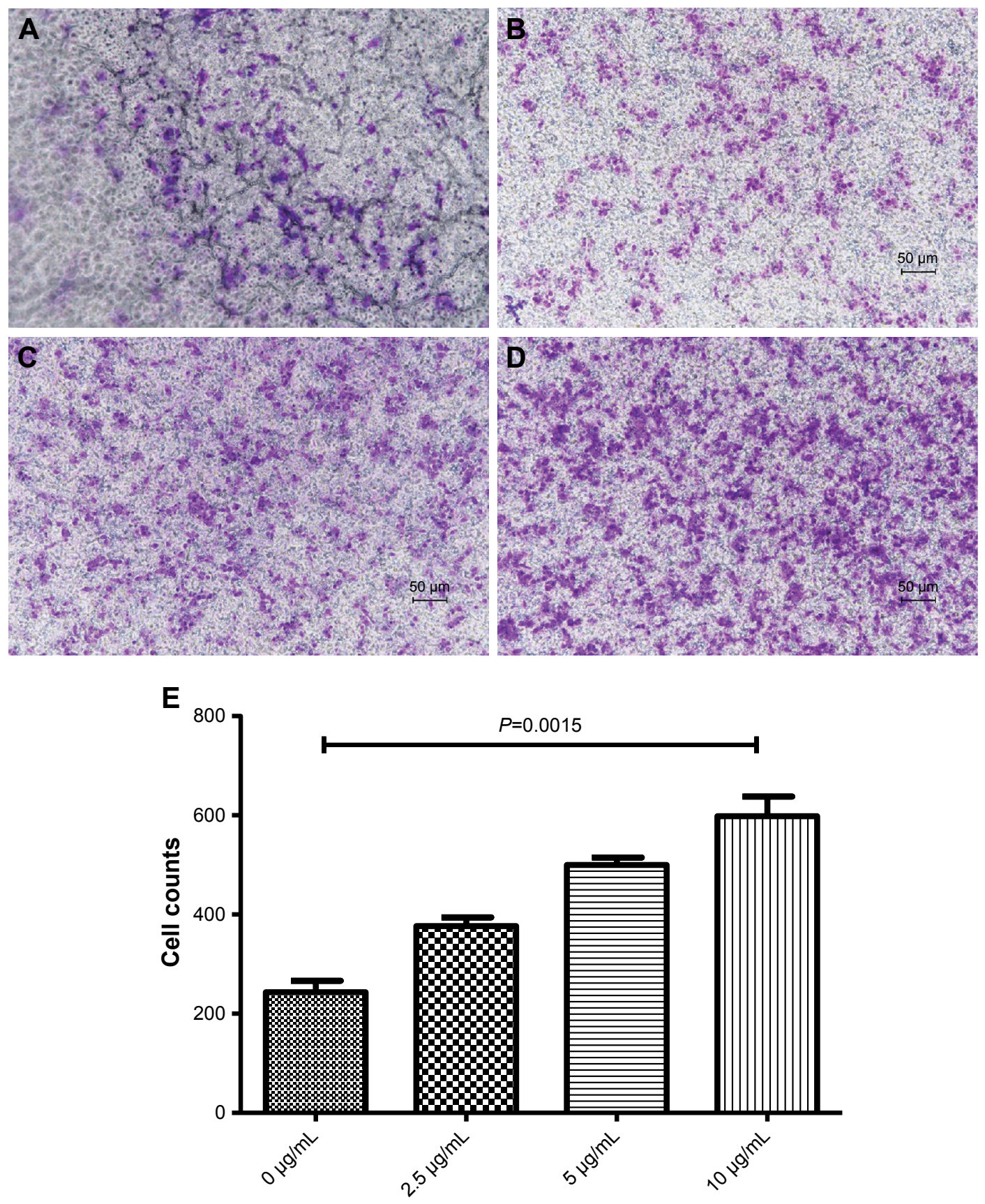

Figure 4 The effect of PD-L2 on cell invasion in the CRC cell line.

Notes: (A-D) Representative images show the migration of HCTII9 cells with the PD-L2 fusion protein. The number of colonies was quantified. The abovementioned experiments were repeated at least three times. (E) The number of migrating cells in different concentrations of the PD-L2 fusion protein. Error bars, mean \pm SD, analysis via Student's t-test.

Abbreviations: CRC, colorectal cancer; PD-L2, programmed-death-I-ligand 2.

a rationale for PD-L2 playing a pivotal role in malignant progression and metastasis, suggesting PD-L2 as a potential therapeutic target in the treatment of CRC.

\section{Acknowledgments}

This work was supported by grants from Jiangsu Province University Outstanding Science and Technology Innovation Team (Grant No 2015023), Qinglan Project (Jing Sun and
Zhong-Wen Sun), and Jiangsu Provincial Medical Youth Talent (Jing Sun). The funders had no role in study design, data collection and analysis, decision to publish, or preparation of the manuscript.

\section{Author contributions}

Research was designed by Jing Sun and Zhong-Wen Sun. Patient samples and data were provided by Yun-Di Guo. 
Construction of TMA and IHC was performed by Peng-Da Guo and Yun-Di Guo. Cell proliferation and migration were performed by Ping-Ping Wu and Jie Yang. Statistical analysis of data was carried out by Yun-Di Guo. The manuscript was critically reviewed by all the authors. The study was supervised by Jing Sun. All authors contributed to data analysis, drafting and revising the article, gave final approval of the version to be published, and agree to be accountable for all aspects of the work.

\section{Disclosure}

The authors report no conflicts of interest in this work.

\section{References}

1. Torre LA, Bray F, Siegel RL, et al. Global cancer statistics, 2012. CA Cancer J Clin. 2015;65(2):87-108.

2. Ferlay J, Soerjomataram I, Dikshit R, et al. Cancer incidence and mortality worldwide: sources, methods and major patterns in GLOBOCAN 2012. Int J Cancer. 2015;136(5):E359-E386.

3. Tseng SY, Otsuji M, Gorski K, et al. B7-DC, a new dendritic cell molecule with potent costimulatory properties for T cells. $J$ Exp Med. 2001;193(7):839-846.

4. Pardoll DM. The blockade of immune checkpoints in cancer immunotherapy. Nat Rev Cancer. 2012;12(4):252-264.

5. Rosenbaum MW, Bledsoe JR, Morales-Oyarvide V, Huynh TG, MinoKenudson M. PD-L1 expression in colorectal cancer is associated with microsatellite instability, BRAF mutation, medullary morphology and cytotoxic tumor-infiltrating lymphocytes. Mod Pathol. 2016; 29(9):1104-1112.

6. Chernova T, Chaudhary D, Borde M, Chernova I, et al. PD-L2 is a second ligand for PD-1 and inhibits T cell activation. Nat Immunol. 2001;2:261-268.

7. Zhang Y, Chung Y, Bishop C, et al. Regulation of $\mathrm{T}$ cell activation and tolerance by PDL2. Proc Natl Acad Sci U S A. 2006;103(31): 11695-11700.

8. Wang S, Bajorath J, Flies DB, Dong H, Honjo T, Chen L. Molecular modeling and functional mapping of B7-H1 and B7-DC uncouple costimulatory function from PD-1 interaction. J Exp Med. 2003;197(9): 1083-1091.

9. Rozali EN, Hato SV, Robinson BW, Lake RA, Lesterhuis WJ. Programmed death ligand 2 in cancer-induced immune suppression. Clin Dev Immunol. 2012;2012.

10. Ishida M, Iwai Y, Tanaka Y, et al. Differential expression of PD-L1 and PD-L2, ligands for an inhibitory receptor PD-1, in the cells of lymphohematopoietic tissues. Immunol Lett. 2002;84(1):57-62.
11. Kaku H, Rothstein TL. Octamer binding protein 2 (Oct2) regulates PD-L2 gene expression in B-1 cells through lineage-specific activity of a unique, intronic promoter. Genes Immun. 2010;11(1):55-66.

12. Zhong X, Tumang JR, Gao W, Bai C, Rothstein TL. PD-L2 expression extends beyond dendritic cells/macrophages to B1 cells enriched for $\mathrm{V}(\mathrm{H}) 11 / \mathrm{V}(\mathrm{H}) 12$ and phosphatidylcholine binding. Eur J Immunol. 2007;37(9):2405-2410.

13. Messal N, Serriari NE, Pastor S, Nunès JA, Olive D. PD-L2 is expressed on activated human $\mathrm{T}$ cells and regulates their function. Mol Immunol. 2011;48(15-16):2214-2219.

14. Yearley JH, Gibson C, Yu N, et al. PD-L2 Expression in Human Tumors: Relevance to Anti-PD-1 Therapy in Cancer. Clin Cancer Res. 2017; 23(12):3158-3167.

15. Okazaki T, Honjo T. PD-1 and PD-1 ligands: from discovery to clinical application. Int Immunol. 2007;19(7):813-824.

16. Gao Q, Wang XY, Qiu SJ, et al. Overexpression of PD-L1 significantly associates with tumor aggressiveness and postoperative recurrence in human hepatocellular carcinoma. Clin Cancer Res. 2009;15(3): 971-979.

17. Wang H, Yao H, Li C, et al. PD-L2 expression in colorectal cancer: Independent prognostic effect and targetability by deglycosylation. Oncoimmunology. 2017;6(7):e1327494.

18. Dong M, Wang HY, Zhao XX, et al. Expression and prognostic roles of PIK3CA, JAK2, PD-L1, and PD-L2 in Epstein-Barr virus-associated gastric carcinoma. Hum Pathol. 2016;53:25-34.

19. Hamanishi J, Mandai M, Iwasaki M, et al. Programmed cell death 1 ligand 1 and tumor-infiltrating CD8+ T lymphocytes are prognostic factors of human ovarian cancer. Proc Natl Acad Sci U S A. 2007;104(9): $3360-3365$.

20. Nomi T, Sho M, Akahori T, et al. Clinical significance and therapeutic potential of the programmed death-1 ligand/programmed death-1 pathway in human pancreatic cancer. Clin Cancer Res. 2007;13(7): 2151-2157.

21. Latchman Y, Wood CR, Chernova T, et al. PD-L2 is a second ligand for PD-1 and inhibits T cell activation. Nat Immunol. 2001;2(3): 261-268.

22. Torphy RJ, Schulick RD, Zhu Y. Newly Emerging Immune Checkpoints: Promises for Future Cancer Therapy. Int J Mol Sci. 2017; 18(12):2642.

23. Li X, Hu W, Zheng X, et al. Emerging immune checkpoints for cancer therapy. Acta Oncol. 2015;54(10):1706-1713.

24. Jung HI, Jeong D, Ji S, et al. Overexpression of PD-L1 and PD-L2 Is Associated with Poor Prognosis in Patients with Hepatocellular Carcinoma. Cancer Res Treat. 2017;49(1):246-254.

25. Xiao Y, Yu S, Zhu B, et al. RGMb is a novel binding partner for PD-L2 and its engagement with PD-L2 promotes respiratory tolerance. J Exp Med. 2014;211(5):943-959.

26. Shi Y, Huang XX, Chen GB, et al. Dragon (RGMb) induces oxaliplatin resistance in colon cancer cells. Oncotarget. 2016;7(30): $48027-48037$.
OncoTargets and Therapy

\section{Publish your work in this journal}

OncoTargets and Therapy is an international, peer-reviewed, open access journal focusing on the pathological basis of all cancers, potential targets for therapy and treatment protocols employed to improve the management of cancer patients. The journal also focuses on the impact of management programs and new therapeutic agents and protocols on

\section{Dovepress}

patient perspectives such as quality of life, adherence and satisfaction. The manuscript management system is completely online and includes a very quick and fair peer-review system, which is all easy to use. Visit http://www.dovepress.com/testimonials.php to read real quotes from published authors. 